\title{
ADVERSE DRUG REACTIONS IN PEDIATRIC PATIENTS IN A TERTIARY CARE HOSPITAL IN KOLLAM
}

\author{
REEJA R, BEENA JS*, AJITHKRISHNAN AS, BINDULATHA NAIR R
}

\author{
Department of Pharmacology, Government Medical College, Kollam, Kerala, India. Email: beena.arun@gmail.com
}

Received: 5 December 2020, Revised and Accepted: 23 February 2020

\begin{abstract}
Objective: Adverse drug reactions have not been as thoroughly studied in children as they have in adults. Extrapolation of efficacy, dosing regimens, and ADRs from adult data are inappropriate owing to developmental changes in physiology and drug handling. There is a lack of local data regarding the potential risk of ADRs in pediatric patients. Objective of this study is to identify the adverse drug reaction (ADR) profile in pediatric patients.
\end{abstract}

Methods: In this cross-sectional study, 450 children attending the pediatric inpatient and outpatient department were selected, and the CDSCO reporting form for suspected ADR reporting forms was collected from those who had any adverse events by the consulting pediatrician. Later, this form was analyzed for the details for ADRs and assessed for causality, severity, and preventability using Naranjo's algorithm, Hartwig and Siegel scale, and modified Schumock and Thornton scale of adverse drug reactions.

Results: The cross-sectional study revealed a prevalence of $12.89 \%$. Antibiotics caused more ADRs than any other group of drugs. Dermatological ADRs were the most common. Most ADRs were not preventable and were of moderate severity. The causality assessment showed that most ADRs were possible category.

Conclusion: The ADRs are often unrecognized. We need more strict monitoring for early detection, treatment, and more importantly prevention of these events in the future. For that, more awareness programs, CMEs and teamwork are extremely important among the caregivers.

Keywords: Pediatric ADR, Pharmacovigilance, Adverse drug reaction, ADR monitoring.

(C) 2021 The Authors. Published by Innovare Academic Sciences Pvt Ltd. This is an open access article under the CC BY license (http://creativecommons.org/ licenses/by/4.0/) DOI: http://dx.doi.org/10.22159/ajpcr.2021v14i4.40453. Journal homepage: https://innovareacademics.in/journals/index.php/ajpcr

\section{INTRODUCTION}

Pharmacovigilance in children requires special attention. Drugs are the mainstay of treatment in pediatric practice, yet a high proportion of drugs has not been tested in children. This leads to irrational prescribing, the use of inappropriate doses, the use of age-inappropriate formulations, which may result in underdosing or overdosing, and drug development without due regard for regular development process of a child. Children are more vulnerable to ADRs as the pharmacokinetics and pharmacodynamics of many commonly used drugs vary significantly in pediatric patients [1]. The joint WHO-UNICEF report of 2006 states: "Children are not small adults when taking a drug." The capacity of absorption, distribution, metabolism, and elimination of a drug is very different between adults and children, and they continue to change during the stage of development $[1,2]$. The purpose is to identify new information about hazards associated with medicines and preventing harm. In consideration of all these, our objective was to find the proportion of adverse drug reaction (ADR) in pediatric patients in a tertiary care hospital and to assess causality, severity, and preventability of adverse drug reactions using various standard scales.

\section{METHODS}

A cross-sectional study was done in the outpatient and inpatient department of Paediatrics, Govt. Medical College, Kollam. All patients of either sex between the ages 0 and 12 years coming as outpatient or who are hospitalized are included in the study. Sample size was determined by the formula $\left[\mathrm{Z} \alpha^{2}\right] \mathrm{pq} \div \mathrm{d}^{2}$, and the sample size has been calculated as 384. All consecutive cases attending pediatric OPD and as inpatients till the sample size is satisfied.

After obtaining IRC and IEC approval for the study, CDSCO-ADR reporting form reported by the pediatricians was collected and analyzed from OPD and IPD. The ADR data were analyzed to find the demographic profile, type of ADR, its severity, frequency of occurrence, drugs implicated, outcome, drug interactions, if any. The causality of ADR was assessed with Naranjo's algorithm scale [3]. The severity of ADRs was assessed by Modified Hartwig and Siegel scale [4]. Examples of ADRs assessed as severe are those that cause death, directly lifethreatening, lengthened hospitalization, or entailed shift to a higher level of clinical care. The preventability of ADR was assessed using Modified Schumock and Thornton scale [5].

\section{RESULTS}

\section{Prevalence of ADRs}

Of the 450 patients studied in pediatric OPD and IPD, we got ADRs in 58 patients. The prevalence of ADR among pediatric patients is $12.89 \%$.

\section{Sociodemographic profile}

$32.8 \%$ of ADRs were reported in children more than 10 years of age as shown in Fig. 1. Mean age was 7.23 years with a SD of 5.28. Among them, $56.9 \%$ were males and $43.1 \%$ were females.

\section{System affected and ADRs reported}

Dermatological system was most commonly affected (44.9\%) followed by gastrointestinal system (43.1\%). Neurological and circulatory ADRs were also reported in $10.3 \%$ and $1.7 \%$, respectively (Fig. 2). Urticaria was the most commonly observed ADR followed by rashes.

\section{Drugs causing ADR}

Among the drugs, antibiotics (56.8\%) were responsible for majority of ADRs since it was the most commonly prescribed drugs (Table 1). Of this, amoxycillin + clavulanic acid caused most ADRs. NSAIDs came next with a percentage of 19 followed by bronchodilators (5.2\%) and antipsychotics (3.4\%). About 3.4\% ADR were noted for an ayurvedic 
preparation (Uramarunnu). Concomitant drug therapy was present for majority of ADRs (56.9\%).

\section{Assessment of ADRs}

The ADRs reported were assessed using Naranjo's algorithm scale [15] (for causality), Modified Hartwig and Siegel scale (for severity), and Modified Schumock and Thornton scale (preventability). The highest causality of ADRs belonged to category possible (51.7\%), followed by probable (46.6\%). Definite was only 1.7\%. Most of ADRs belonged to a Naranjo score of 2 and 3 (both 31.03\%) (Tables 2 and 3).

Considering the preventability, most of the ADRs were not preventable (56.9\%), followed by probably preventable (29.3\%). Nearly $13.8 \%$ of ADRs were definitely preventable (Fig. 3).

About $75.9 \%$ of the ADRs was of moderate severity (severity level 3 followed by $4 \mathrm{a}$ ) followed by $24.1 \%$ mild ADRs. No severe ADRs were reported (Table 4 and Fig. 4).

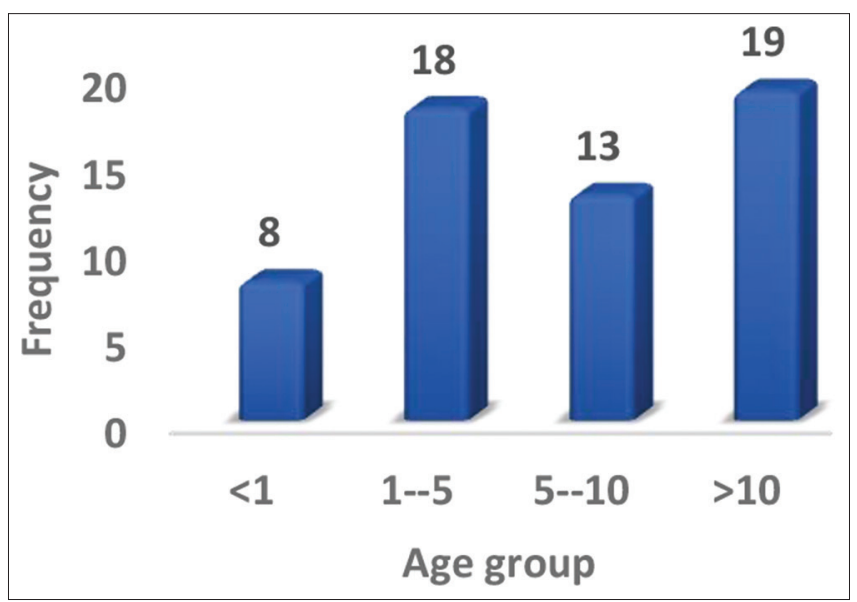

Fig. 1: Age distribution

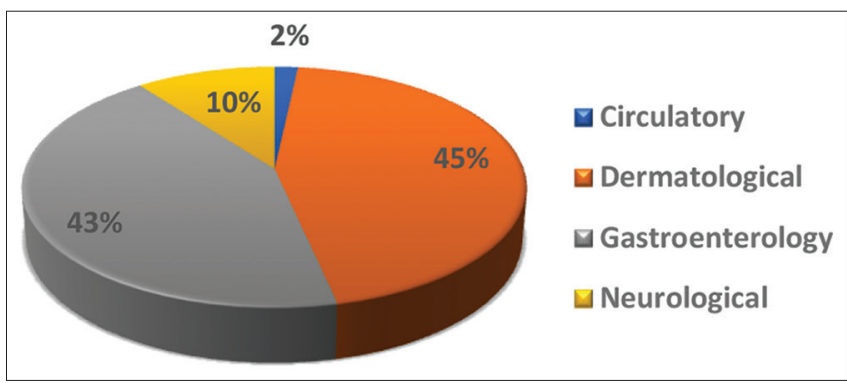

Fig. 2: System-wise distribution of ADRs reported

Table 1: Drugs with most reported ADRs

\begin{tabular}{lll}
\hline Drug class & Frequency $(\mathbf{n = 5 8 )}$ & Percentage \\
\hline Antacid & 1 & 1.7 \\
Antibiotic & 30 & 51.7 \\
Antibiotic tubercular & 2 & 3.4 \\
Antifungal & 1 & 1.7 \\
Antihistamine & 1 & 1.7 \\
Antipsychotic & 2 & 3.4 \\
Antiulcer & 1 & 1.7 \\
Antiviral & 2 & 3.4 \\
Ayurvedic & 2 & 3.4 \\
Bronchodilator & 3 & 5.2 \\
Decongestant & 1 & 1.7 \\
NSAID & 11 & 19.0 \\
Vaccine & 1 & 1.7 \\
\hline
\end{tabular}

\section{DISCUSSION}

Of the 450 patients studied in pediatric OPD and IPD, we got ADRs in 58 patients. Hence, the prevalence of ADR among pediatric patients is $12.89 \%$. The prevalence was low compared to the study by Mandha et al [6] and Clavenna et al [7]. The tertiary care center where the study was done started only in the year 2016 and is still in the infant stage. Inadequate manpower in all the sectors including doctors, nurses, and pharmacists may have contributed to the low prevalence. Lack of awareness about pharmacovigilance program was also an important reason. Maximum number of ADRs were reported by treating pediatricians followed by nurses.

In the present study, $32.8 \%$ of ADRs were reported in children more than 10 years of age. This was in contrast to study by Priyadarsini et al. [8] and Khan et al. [9]. Among them, $56.9 \%$ were males and $43.1 \%$ were females.

Dermatological system was most commonly affected (44.9\%) followed by gastrointestinal system (43.1\%). Neurological and circulatory ADRs were also reported in $10.3 \%$ and $1.7 \%$, respectively. This was in accordance with study by Priyadarsini et al., Khan et al., and Mandha et al. Most common ADR reported was urticaria followed by rashes and diarrhea. More ADRs were reported for oral medications compared to parenteral route. This may be due to low admission rate in our hospital due to lack of infrastructure and manpower at that time.

In the present study, antibiotics (56.8\%) were responsible for majority of ADRs since it was the most commonly prescribed drugs. Of this, amoxycillin + clavulanic acid caused most ADRs as it was the readily available antibiotic in government supply. Similar results were obtained in studies by Mandha et al [6], Shamim M et al [10] where beta lactams were the commonest antibiotic causing ADRs. NSAIDs came next with a percentage of 19 followed by bronchodilators (5.2\%) and antipsychotics (3.4\%). 3.4\% ADR were noted for an ayurvedic preparation (Uramarunnu) as a good percentage of population belong to rural area with traditional beliefs. Concomitant drug therapy was present for majority of ADRs (56.9\%).

The ADRs reported were assessed using Naranjo's algorithm scale (for causality), Modified Hartwig and Siegel scale (for severity), and

Table 2: Causality assessment

\begin{tabular}{lll}
\hline Causality & Frequency & Percentage \\
\hline Definite & 1 & 1.7 \\
Possible & 30 & 51.7 \\
Probable & 27 & 46.6 \\
Total & 58 & 100.0 \\
\hline
\end{tabular}

Table 3: Naranjo scores of the ADR reported

\begin{tabular}{lll}
\hline Naranjo score & Frequency & Percentage \\
\hline 2 & 18 & 31.03 \\
3 & 18 & 31.03 \\
4 & 10 & 17.24 \\
5 & 7 & 12.07 \\
6 & 2 & 3.45 \\
7 & 2 & 3.45 \\
9 & 1 & 1.72 \\
Total & 58 & 100.0 \\
\hline
\end{tabular}

Table 4: Analysis of ADRs based on severity

\begin{tabular}{lll}
\hline Severity & Frequency & Percentage \\
\hline Mild & 14 & 24.1 \\
Moderate & 44 & 75.9 \\
Total & 58 & 100.0 \\
\hline
\end{tabular}




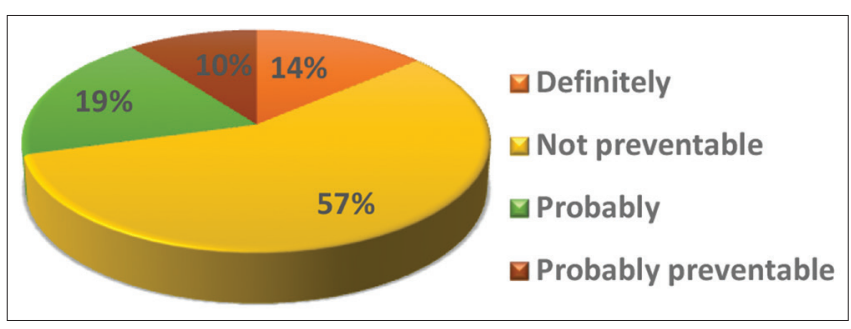

Fig. 3: Preventability criteria

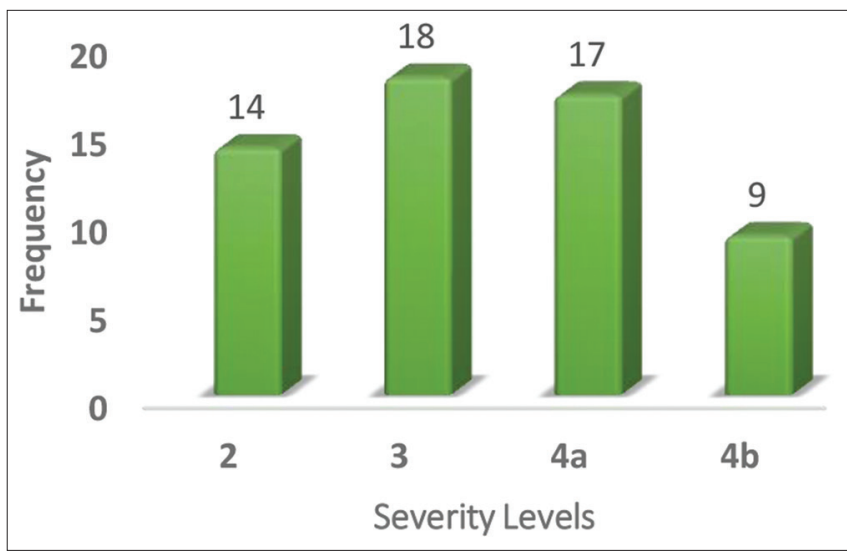

Fig. 4: Severity levels of ADRs reported

Modified Schumock and Thornton scale (preventability). The highest causality scores of ADRs were possible (51.7\%), followed by probable (46.6\%). Definite was only $1.7 \%$. Most of ADRs belonged to a Naranjo score of 2 and 3 (both $31.03 \%$ ) Considering the preventability, most of the ADRs were not preventable (56.9\%), followed by probably preventable (29.3\%). About $13.8 \%$ of ADRs were definitely preventable. Almost $75.9 \%$ of the ADRs were of moderate severity (severity level 3 followed by $4 \mathrm{a}$ ) followed by $24.1 \%$ mild ADRs. No severe ADRs were reported. Severe ADRs are generally not observed and are rare in recent studies also $[5,6,10]$. This was in accordance with study by Mandha et al. and Digra et al. [13].

\section{CONCLUSION}

The joint WHO-UNICEF report of 2006 states: "Children are not small adults when taking a drug." ADRs are one of the major causes of iatrogenic diseases which are often unrecognized and underreported. In the study, majority of ADRs were reported among children more than 10 years. Antibiotics contributed more to the ADRs followed by NSAIDs. Most of the reactions were of moderate severity. This stipulates the need for regular and strict ADR monitoring among children to ensure the safety of drug therapy. Family pediatricians can play very important role in reporting suspected ADRs in harmony with pharmacovigilance projects. Risk management programs along with active observation will help to plan effective steps in the future reducing risks for the community [3]. Pharmacovigilance awareness programs should be conducted among various levels of health-care professionals to enhance the impact of understanding and spontaneous reporting of ADRs [14].

\section{AUTHORS CONTRIBUTION}

The study design and concept were done by Dr. Reeja R and Dr. Beena JS. And Dr. Reeja R wrote the paper, performed data collection, performed data analysis, drafted the manuscript, and contributed to the final manuscript. Dr. Beena JS cowrote the paper, drafted the manuscript, and contributed to the final manuscript. Dr. Ajithkrishnan AS helped in data collection and made it feasible. Dr. Bindulatha Nair R supervised the research and contributed to the final manuscript.

\section{CONFLICTS OF INTEREST}

The authors declare no conflicts of interest.

\section{AUTHORS FUNDING}

SBMR (State Board of Medical Research) funding was availed for the research.

\section{REFERENCES}

1. Chien JY, Ho RJ. Drug delivery trends in clinical trials and translational medicine: Evaluation of pharmacokinetic properties in special populations. J Pharm Sci 2011;100:53-8.

2. Kearns GL, Abdel-Rahman S, Alander SW, Blowey DL, Leeder JS, Kauffman RE. Developmental pharmacology-drug disposition, action, and therapy in infants and children. N Engl J Med 2003;349:1157-67.

3. Naranjo CA, Busto U, Sellers P, Ruiz I, Roberts EA, Janecek E, Domecq C, et al. A method for estimating the probability of adverse drug reactions. Clin Pharmacol Ther 1981;30:239-45.

4. Hartwig SC, Siegel J, Schneider PJ. Preventability and severity assessment in reporting adverse drug reactions. Am J Hosp Pharm 1992;49:2229-32.

5. Schumock GT, Thornton J. Focusing on the Preventability of adverse drug reactions. Hosp Pharm 1992;27:538

6. Mandha M, Reddy KP, Reddy KR. Evaluation of adverse drug reactions in pediatric patients. Indian J Pharm Pract 2013;6:32-5.

7. Clavenna A, Bonati M. Adverse drug reactions in childhood: A review of prospective studies and safety alerts. Arch Dis Child 2009;94:724-8.

8. Priyadharsini R, Surendiran A, Adithan C. A study of adverse drug reactions in pediatric patients. J Pharmacol Pharmacother 2011;2:277-80.

9. Khan LM, Al-Harthi SE, Saadah OI. Adverse drug reactions in hospitalized pediatric patients of Saudi Arabian University Hospital and impact of pharmacovigilance in reporting ADR. Saudi Pharm J 2013;21:261-6.

10. Shamim M, Ali MD, Alam MS, Ali MS, Ahmad S, Ansari MS. Drug utilization based adrs detection of antibiotics prescribed for LRTI in tertiary care teaching hospital, New Delhi. Int J Pharm Pharm Sci 2018;10:7-14.

11. Napoleone E. Medicines for children ADRs: From spontaneous reporting to active surveillance. Child Care Health Dev 2009;36:106-7.

12. Digra KK, Pandita A, Salini GS, Bharti R. Pattern of adverse drug reactions in children attending the department of pediatrics in a tertiary care center: A prospective observational study. Clin Med Insights Ped 2015;9:73-8

13. Smyth RM, Gargon E, Kirkham J, Cresswell L, Golder S, Smyth R, et al. Adverse drug reactions in children-a systematic review. PLoS One 2012;3:e24061.

14. Kumar L. Pharmacovigilance/reporting adverse drug reactions: An approach to enhance health surveillance and extending market share by minimizing the chances of drug withdrawals. Int J Pharm Pharm Sci 2015;7:1-7.

15. Castro-Pastrana LI, Carleton BC. Improving pediatric drug safety: Need for more efficient clinical translation of pharmacovigilance knowledge. J Popul Ther Clin Pharmacol 2011;18:e76-88. 